\title{
Beata Sirowy \\ Among paradigms: Major ways of framing user-related problems in contemporary architectural discourse
}

\begin{abstract}
While a review of contemporary architectural theory indicates that user-related concerns have not been absent, this discussion remains rather fragmented and incidental. Seeking reasons behind this situation, this paper discusses the major paradigms underpinning contemporary architectural discourse and explicates how different paradigms ground different approaches to users. It reveals certain limitations of the dominating conceptual positions (positivism/postpositivism, critical theory, constructivism), and argues in turn for the relevance of phenomenology in supporting a more user- and context-sensitive architectural practice.
\end{abstract}

Keywords: phenomenology, architectural theory, user involvement, paradigms

\section{Introduction}

Martin Heidegger in his lecture "Building, Dwelling, Thinking" (1951) argues that the essential task of architecture is not solely appeasing the "hunger" of houses, but satisfying human's deepest, existential needs; it means to establish a meaningful relationship with the surrounding world, to grow as human beings. The activity of building allows us to gather elements of our existential space and concretise, embody them in our environment. Following from this, the responsibility of architects lies not primarily in the design of static artefacts, but in the creation of spatial, and hence social, relationships contributing to the well-being of the inhabitants.

Although a review of contemporary architectural theory indicates that user-related concerns have not been absent, this discussion remains rather fragmented and incidental. The Modern Movement, despite being dedicated to social ideals, disregarded inhabitants' perspectives and imposed on them arbitrary solutions. More recently, one can observe a tendency to conceive architecture as an intellectualised, abstract exploration of form, as free from any traditional constraints as possible (Eisenman, 1984; Tschumi, 1994). Another tendency is to abandon critical discussions and view architecture as a pragmatic activity that should follow globalisation processes and submit to market forces (Koolhaas \& Mau, 1995; Somol \& Whiting, 2002; Lavin, 2005). All of these approaches marginalise, if not neglect, the needs of inhabitants and the specificity of a given place. Seeking reasons behind this situation, this paper scrutinises the major paradigms underpinning architectural discourse, explicating how they ground different approaches to architecture in general, and more specifically, to the individuals affected by architectural choices - the users of architecture.

At this point, it has to be acknowledged that a clear, unambiguous definition of "users" of architecture may be problematic. As Donald Schön (1983) asserts, one of the challenges in the professional-client relationship lays in specifying "to whom should we define ourselves as standing in the essential professional relationship" (Schön, 1991, p. 291). Eason (1987) identifies three types of users: primary, secondary, and tertiary. Primary users are those persons who actually use the artefact; secondary users are those who will occasionally use the artefact or those who use it through an intermediary; and tertiary users are persons who will be affected by the use of the artefact. In this paper, it is assumed that a successful design should take into account the wide range of possible users. From this perspective, a user-oriented architectural practice is inevitably a practice that not only respects the needs of individuals, but also responds to a given 
context of design and takes part in the existing culture.

Finally, it is worthwhile to indicate that in qualitative research, which is fundamentally an interpretive type of research, the picture given is never value-free. On the contrary, data are unavoidably filtered through the personal values, biases, and interests of the inquirer. In this paper, the author represents a phenomenological perspective.

\section{Why paradigms?}

In architecture, the way of conceptualising the user (as well as any other phenomenon) is dependent upon an adopted philosophical framework defined by a set of basic assumptions regarding the nature of reality and knowledge - a theoretical position, which may also be referred to as a paradigm. An adopted paradigm guides research at every stage, from the selection of a problem to be studied and the methods used for data collection and analysis, until the final stage of interpreting the findings and drawing conclusions (Guba \& Lincoln, 1994). In other words, paradigms are crucial to any scientific project, because their basic assumptions "necessarily dictate the type of research and theories generated" (Yanchar \& Hill, 2003, p. 12). In our case, the basic assumptions of different paradigms "dictate" different approaches to users in architecture.

As Donald Schön (1983) suggests, an awareness of paradigms is beneficial not only for scholars, but also for practitioners. He argues that professionals who are unaware of their way of framing problems do not experience the need to choose among different possibilities. They do not reflect on the way in which they conceptualise the reality in which they function, because for them it is simply the "given reality."

When a practitioner becomes aware of his frames, he also becomes aware of the possibility of alternative ways of framing the reality of his practice. He takes note of the values and norms to which he has given priority, and those he has given less importance, or left out of account altogether. Frame awareness tends to entrain awareness of dilemmas. (Schön, 1991, p. 310)

According to Schön, discussions on different frameworks are typically too focused on a polemics - the advocates of various perspectives rather than reflecting on their frames, act from them, seeking primarily to defend their view and attack the opponents (1991, p. 312).

In the human sciences, one can distinguish several competing paradigms. These paradigms have had an essential influence on architectural discourse. As Kate Nesbitt emphasises, in the introduction to her anthology Theorizing a New Agenda for Architecture, the postmodern period in architecture is defined by a proliferation of paradigms imported from other disciplines (1996, p. 28). In addition, Michael Hays argues, in his anthology Architecture Theory since 1968, that contemporary architectural debates are structured by the primary paradigms of human sciences (1998, pp. xiii-xiv). Nevertheless, it is a challenging task to classify architectural theories according to their founding paradigms. The paradigms are often taken for granted - not explicitly referred to in architectural research. Therefore, a critical evaluation of specific architectural theories demands the effort of looking at their meta-level. A more essential problem is the risk of oversimplification: paradigms adapted into architectural theories hardly ever remain in their original form. This is also the case to some extent for social sciences - there are sometimes problems separating research by paradigms, applied research especially tends to be grounded in more than one paradigm (Willis, Jost, \& Nilakanta, 2007, pp. 80-81). Moreover, the same notions in different paradigms may have different meanings. Therefore, one has to be very careful when generalising across different frameworks. 
Nevertheless, such attempts are needed in order to establish the basis for an informed debate. As Paul-Alan Johnson (1994) asserts, the conceptual underpinnings of architectural theories are too seldom made explicit, "too much is taken for granted or is presumptuous or pompous in architectural writing and theorizing" (p. xviii). Reducing architectural theories to the point of basic conceptions and subjecting them to close scrutiny "empowers those who are attempting to comprehend them over and against those who profess to be already "in-the-know" ... and the result is that "more are informed and fewer are deceived by rhetoric" (Johnson, 1994, p. xviii). Diana Agrest (1991) makes a similar observation:

To render the theoretical instrumentality explicit, from the conception of a theory to its methodological procedures, is of major importance in critical work, particularly at the juncture when this analysis enters the public realm, in order to avoid the ideological effects of such discourse. (Agrest, 1991, p. 8)

In the following section of the text, I will give an overview of the major paradigms underpinning architectural debate: positivism/postpositivism, critical theory, constructivism, and phenomenology, indicating how the basic assumptions of these paradigms may be linked to different approaches to users of architecture. Postmodernism will not be referred to as a separate paradigm. As Willis et al. (2007) observe, the problems with defining postmodernism result from its heterogeneity; it is not a consistent paradigm that can be clearly defined in terms of its ontological, epistemological, and methodological claims, but rather a cross-paradigm view, staying in opposition to most of the positivist/postpositivist assumptions and referring primarily to constructivism and critical theory, but also to some extent to phenomenology. The way of utilising specific paradigms and combining their assumptions varies from author to author.

The structure of each of the proceeding chapters is as follows. The introductory section gives an outline of the key features of a given paradigm. Then, the discussion advances to the paradigm's influences on architectural theory. The final section focuses specifically on the implications of a given paradigm for the role of users in architecture.

\section{Positivism and postpositivism}

\section{Basic characteristics}

Positivism in philosophy is most generally defined as any system that confines itself to the data of experience and excludes a priori or metaphysical speculations. The basic affirmations of positivism are that all knowledge regarding the realm of fact is based on the "positive" data of experience (that "mirror" the reality); and that beyond the realm of fact is only that of logic and mathematics. Positivists became noted for their rejection of metaphysics, i.e., of speculation regarding the nature of reality that goes radically beyond any possible evidence that could either support or refute such "transcendent" knowledge claims.

On the ontological level, positivists consider reality an objective sphere, fully independent from the human mind but accessible to it. This view is often labelled as "naïve realism" (Guba \& Lincoln, 1994).

On the epistemological level, positivists believe that we can come to know something only by experience of the real world or deduction. Collected data are considered as value-free, as a "mirror" of reality; i.e., a researcher is capable of studying an object without influencing it. Research reflects the true nature of the world (a correspondence theory of truth is adopted). The purpose of the research is to find universal laws, as well as to explain, predict, and control the phenomenon under inquiry. Positivist epistemology can be characterised as "dualist and 
objectivist" (Guba \& Lincoln, 1994).

On the methodological level, positivists hold that objectivism and a strict control of the research situation are possible when prescribed procedures are rigorously followed. Thus, the use of a precise, scientific method is advocated. Guba and Lincoln (1994) characterise positivist methodology as experimental and manipulative, focused on verification of hypotheses. Positivists emphasise that all research should start from clearly stated problems and well-defined methods.

Positivism as a way of thinking that accepts no mythic dimension as legitimate is particular to the $19^{\text {th }}$ century and later. Yet, rational and empirical interests can be traced back at least to the Renaissance, with its emphasis on experimentation and observation. The change in the worldview that took place in that period may be described as a transition from the focus on the subject and its destiny, to the investigation of the objective world. The modern transformations have been among others related to the works of Galileo and Descartes. Galileo initiated the "mathematisation of nature"; he believed that nature could be fully described by mathematical models. Descartes established a dualist approach, by making a sharp distinction between the objective sphere, i.e., the outer domain of nature (res extensa) and the subjective sphere, i.e., the inner domain of mind (res cogitans).

The most radical form of positivism is "logical positivism," a position that was developed by the Vienna Circle - a group of scientists and philosophers (who, among others, included Moriz Schlick, Rudolf Carnap, Carl Gustav Hempel, and Otto Neurath). After the Nazis came to power in Austria, several members of the Vienna Circle moved to the USA and had a profound influence on American philosophy, both before and after the war. Conceptually, logical positivism is a modern reformulation of Locke and Bacon's empiricism (the members of the Vienna Circle were also called "logical empiricists"). The main assertion is that there are only two sources of knowledge: logical reasoning on the one hand and sense experience on the other hand. Experience, however, was the main focus of the group. The Vienna Circle worked out a very precise version of universal scientific method, specifying how it could be used to advance knowledge in any discipline, including human sciences. They also proposed the "verification principle," i.e., if there is no way to specify whether a given statement is true or false, then the statement has no meaning and therefore no place in science. As the only knowledge that was valid was scientific knowledge, great areas of philosophical discourse (such as ethics and metaphysics) were considered meaningless and unworthy of any discussion.

In the 1930s and 1940s, Karl Popper published several critiques of logical positivism. He pointed out that the gathered data do not always adequately represent the reality, so there is no guarantee that we can attain truth through well-designed experiments. Popper proposed the "falsification principle" instead of the "verification principle." In it, he argued that data that disprove a hypothesis are far more definitive than data that support it. Popper's theory is the foundation of a modified version of positivism, "postpositivism." Among other important theories that influenced the rethinking of positivist assumptions was Gödel's incompleteness theorem, proved in 1931, which showed that the consistency of a formal language was only obtainable at the price of its limited expressiveness. Gödel helped to release mathematics from the illusion that it could represent the world in a complete and consistent way. Another essential contribution was from Wittgenstein, who in his Philosophical Investigations (1953) reinforced the view that mathematics was a part of human history and not an abstract ideal independent of it.

While positivists are convinced that by conducting scientific research we are able to discover the way things really are (scientific theories reflect the true nature of the world), postpositivists acknowledge that it is not possible to apprehend reality as it is and attain an absolute certainty that a given theory is true. Confirming experiments do not prove a theory, they 
only add some evidence that supports the theory. However, a carefully conducted study that does not support a theory provides a strong argument to believe that the theory is incorrect. In this view, objectivity is a "regulatory ideal" in that we can never be sure that a theory is true, but we can get closer and closer to truth by a series of research studies (Guba \& Lincoln, 1994; Willis et al., 2007). Another difference between positivism and postpositivism concerns the neutrality of collected data. Positivists believe that it is possible to collect objective, theory-free data and use them to develop a theory. However, postpositivists acknowledge that the collection and interpretation of data may be influenced by a theory and the values of the researcher to some extent. Nevertheless, the overall purpose of postpositivist research remains the same as in the positivist framework: to discover universal laws through the use of scientific method (Willis et al., 2007, pp. 72-73).

Ontologically, the postpositivist position may be described as "critical realism"; epistemologically, as "modified dualism/objectivism". Methodologically, it can be characterised by "critical multiplism" as a way of falsifying hypotheses; this includes a greater variety of data sources and an increased utilisation of qualitative techniques, e.g., taking into account the meanings that people ascribe to their actions or describing the research context (Guba \& Lincoln, 1994, p. 110).

\section{Positivism/postpositivism and structuralism}

Discussing the influence of positivism/postpositivism on architectural research, it is worthwhile to look briefly at structuralism. Structuralism, roughly speaking, is a way of thinking about culture in terms of structures. Its aim, in different spheres of culture (such as religion, architecture, politics, etc.) is analogous to what grammar does for language -

to explain how these systems work and how they generate meanings for their users. Although defining structuralism as a form of positivism would be an oversimplification ${ }^{1}$, structuralism may be rightly classified as a continuation of some aspects of the positivist/postpositivist tradition. Its task was to find an objective, rational, and scientific methodology for analysing the data of perception.

Ferdinand de Saussure's lectures, held at the University of Geneva between 1906 and 1911, are regarded as the starting point of structuralism. After de Saussure's death, these lectures were published by his students and colleagues under the title Course in General Linguistics (1916). De Saussure's main focus was not on the use of language ("parole" or speech), but rather on the underlying structure of language ("langue"). He called his theory semiology.

Structuralism emerged out of the difficulties of positivism in dealing with the human sciences. The refutation of "metaphysics" by positivists made the conception of any kind of "meaning" within social and psychological phenomena untenable. Structuralism may also be seen as a response to the need to account for the deep structural crises and transformative processes, which manifested in the late $19^{\text {th }}$ century in Europe, for which positivism was inadequate. Further on, structuralism was influenced by the same processes that led to the development of the postpositivist position.

Although structuralism's origins reach back as early as the beginning of the $20^{\text {th }}$ century, it gained the most popularity within academia in the 1960s and 1970s. Researchers within this tradition constructed their models of culture employing structural linguistics and mathematical concepts of structure. The aim of the research was to determine and prove laws governing the structure of social relations. Although Lévi-Strauss denied that structuralism was solely for the purpose of applying mathematics, he did so, limiting the domain of mathematics to its traditional "metric" aspects, such as number and magnitude. Mathematics is a constantly developing branch 
of knowledge and has long since surpassed this limitation. When one considers the more recent developments within mathematics (symbolic logic, complexity theory, set theory, group theory, cybernetics, information theory, games theory, topology, etc.) structuralism can be more rightly characterised as the "mathematisation" of a given object.

\section{Influence on architectural discourse}

The positivist line of thinking in architectural theory started in the $17^{\text {th }}$ century with Claude Perrault, "the first modern," whose abstract and normative theories of proportion can be related to the astronomy of Galileo. The tendency towards abstraction, logic, mathematics, and technological systems in architecture was continued by Jean-Nicolas-Louis Durand and l'Ecole Polythechnique in 1800 (Pérez-Gómez, 1983).

In the pre-war period, architects associated with the Bauhaus School self-consciously sought to articulate a view of the world in which logical positivism played an essential role. Throughout their writings, the members of the Vienna Circle pointed to modern architecture as the cultural movement with which they most identified. Furthermore, "their interests were reciprocated as the logical positivists were more prominent as visitors to the Dessau Bauhaus than members of any other single group outside art and architecture" (Galison, 1990, p. 710). Discussing logical positivism and Bauhaus, Galison states:

Both enterprises sought to instantiate a modernism emphasizing what I will call "transparent construction," a manifest building up from simple elements to all higher forms that would, by virtue of the systematic constructional program itself, guarantee the exclusion of the decorative, mystical, or metaphysical. (Galison, 1990, p. 710)

Referring to simple observational reports ("protocol statements") and logical connectives (such as if, then, or, and), the logical positivists intended to ground a valid knowledge. Following this direction, "the Bauhaus School hoped to use scientific principles to combine primitive colour relations and basic geometrical forms to eliminate the decorative and create a new aesthetic that would prize functionality" (Galison, 1990, p. 711). The following statement of Theo van Doesburg is representative of the Bauhaus' approach:

The work of art must be entirely conceived and formed by the mind before its execution. It must receive nothing from nature's given forms or from sensuality or from sentimentality. We wish to exclude lyricism, dramaticism, symbolism, etc. In painting a pictorial element has no other element than itself. The construction of the picture, as well as its elements, must be simple and visually controllable. Technique must be mechanical, that is exact, anti-impressionistic. (Van Doesburg, 1931, as cited in Osborne, 1979, p. 128)

Yet, even though many similarities may be identified between logical positivism and the Bauhaus School, the wide range of ideas represented by the School cannot be reduced exclusively to the positivist influence. As Marcel Franciscono in his analysis of the early Bauhaus observes, "From the beginning it was a tangled skein of various and even conflicting motives and tendencies" (1971, p. 240). Supporting this statement, Joseph Rykwert in the essay "The Dark Side of Bauhaus" in The Necessity of Artifice (1982) remarks:

I hope that I will not risk paradox if I now accuse the Bauhaus masters - not of an excessive rationalism - but rather of not stating the religious, or quasi-religious postulates for what they were doing; or at any rate of not stating them explicitly. Only Itten and Klee have a clean record 
in this respect; and they were the two Bauhaus masters who realized most clearly the danger of van Doesburg's excessive devotion to modernity; to interpreting every technological advance as a spiritual leap forward. (Rykwert, 1982, as cited in Harries, 1997, p. 391)

In the post-war period, until the early 1960s, positivism had a dominating influence on architectural theory. The ideals of International Style (e.g., rationalisation of architectural production; functionalism; lack of interest in historical and cultural context; focus on new technologies) have their origins in positivism. There is still a considerable representation of positivism/postpositivism in contemporary research dealing with the "science of building" technological aspects of architecture. It can also be traced in architectural theories related to behaviourism, operations research and system theory.

The postpositivist perspective within architectural research is often combined with structuralist ideas. Structuralism entered architectural debate in the early 1950s as a response to modern functionalism (Frampton, 1994, pp. 272-276). While both frameworks promise empirically confirmable data and may be considered as a form of determinism, one of the most important differences is the philosophical issue of reductionism, i.e. the position that the best scientific strategy is to approach complex phenomena in terms of their smallest possible elements. An example of reductionism in architecture is analysing a building in terms of spaces, each of which is assigned a single, static function, without taking into account that spaces can carry meaning for their inhabitants (this was the approach of functionalism). One consequence of functionalist reductionism was monotony and sterility of designed spaces and following on from that, a lack of identification by the user with her/his surroundings. Structuralism, on the contrary, acknowledges the importance of socio-cultural studies in its analysis of the built environment, thus it encourages a more dynamic and holistic view of design where meanings carried by spaces to their inhabitants have to be taken into account.

However, there are two different ways of adapting structuralism in architecture. On the one hand, there is the "aesthetics of number," translating structuralist concepts directly into aesthetic qualities, which is a form of reductionism. On the other hand, a more careful interpretation of structuralism (within the postpositivist paradigm) resulted in the space syntax theory, elaborated on in the late 1970s by Bill Hillier and Julienne Hanson. This theory was developed as a tool to help architects to simulate the likely social effects of their designs. The main assumption was that spaces can be broken down into components, analysed as networks of choices, and then represented in a graphic form that describes the relative connectivity and integration of those spaces.

Christopher Alexander's "pattern language," created in the 1970s, is another example of postpositivist/structuralist-influenced thinking aimed at the creation of an "architecture of living variety." The purpose of employing scientific concepts in architecture, according to Alexander, is "to enable us to create deeper structure - and that means more satisfying design, more eternal forms, more valuable places, more beautiful buildings" (2004, para 2). Alexander's recent research, conducted in close cooperation with the mathematician Nikos Salingaros, continues the line of investigation started with A Pattern Language in the perspective of complexity theory. In his monumental work, The Nature of Order (2002-2005), Alexander argues that the same laws apply to all structures in the universe; from atoms and crystals to living forms, and even to galaxies. The same set of laws determines the structure of a city; a building; or a single room. In their approach, Alexander and Salingaros combine scientific analyses and structuralist ideas with an intuitive experience - aiming to describe architecture that is more adaptive to human needs and aspirations. They emphasise that the success of architecture should be measured in human 
terms, i.e., in terms of the physical and emotional well-being of the residents. The role of science is to provide architects with useful tools to realise this aim.

Structuralism may be seen as the main foundation of a postmodern turn in architecture. Its greatest impact was through semiotics - a field of study that analyses systems of signs, codes, and conventions in all domains of human activity, distinguishing three basic components of language: the word (sign), its symbol (signifier), and what the symbol stands for (the signified). From the semiotic perspective, what the author meant by the text has a very limited relevance to the actual meaning of the text. With regards to architecture, a building can come to signify more, or something completely different, than its designer meant. Structuralism, in attacking the International Style, argued that it is not possible to design solely for function, in the aesthetics that symbolises nothing but function (as functionalists claimed). All objects function as signs, and their meaning can never be fully dependent upon their creators.

Structuralism lost much of its influence on architectural theory around the mid-1980s with the proliferation of interpretive techniques that cut across traditional oppositions (such as signified/signifier, interiority/exteriority) and opened the subject to a more radical heterogeneity (Hays, 1998, p. xiii). This tendency had already begun in the mid-1970s with the emergence of poststructuralism and the dogma that reality is a social construction, determined and explained by the contingencies of its time and place, and based on no underlying constants or essences. From this perspective, structuralism becomes a series of systematic, scientific projects; semiotics is defined as the "science" of signs. Poststructuralists focus on critiques of these projects, or explorations of their ultimate impossibility.

\section{Implications for user involvement}

It seems that the main reason behind the neglect of the user's perspective in positivist/postpositivist frameworks is their predominant emphasis on quantitatively measurable phenomena and scientific knowledge, resulting in a reductionist approach to the sphere of human meanings and significations. Dualist thinking, the key characteristic of positivist approaches, separates regular, predictable, and controllable events of the corporal world from those that are not certain, and are difficult to predict, i.e., related to human consciousness. Priority is always given to "objectivity" (represented by a scientist, an expert, a professional, etc.), and "subjectivity" is associated with a problem of bias, a distortion of an observation caused by the subject. Furthermore, the subject is not regarded as a social subject, influenced and shaped by membership in a community, but as a "private subject", an individual, whose purposes and attitudes originate within herself. Consequently, architects largely disregarded not only a user's perspective, but also cultural and historical contexts of designed artefacts. As Kostoff indicates, socially-oriented practitioners referring to the needs of users typically imposed on them arbitrary solutions.

Modernist rhetoric waxed eloquent about the needs of users. It represented architecture as the vehicle of social welfare and set public housing issues as the highest priority of architecture. But there was no question of consulting with the user of the housing estate during the course of their design. [...] [U]sers did not know what they wanted or, more importantly, what they should have. Their collective needs, interpreted by the architect and the sponsoring agency, would be codified in the 'program' - as had been the case with hospitals, schools and prisons in the past. The fit might not be comfortable at first. The setting might appear alien to our habitual ways. The fault was with our habits. We would learn to adjust to the new Wohnkultur because it was based on rationally derived standards. [...] Architectural revolutions required the redesign of humanity. (Kostoff, 1989, as cited in Stevens, 1998, pp. 13-14) 
In addition, some scholars point out that the representation of social reality produced by positivism is inherently conservative, helping to support the status quo (i.e., the marginal role of users of architecture) rather than challenging it. As the Frankfurt School (particularly Horkheimer) argues, science has always been at the service of the dominant culture and has been used for the more efficient exercise and administration of power. One aspect of this process is prioritising the rigour of the research design over the important issues in the research process, e.g., the subject matter and the purpose of particular domains of knowledge. Yanchar and Hill (2003) call this phenomenon "methodolatry." They state that "method has been exalted nearly to the point of being an end in itself" (p. 15). A strong methodological emphasis can also be observed in positivism-inspired architectural movements.

It has to be noted that some architectural adaptations of structuralism particularly stress the issue of user participation in housing design. John Habraken, Herman Hertzberger and Lucien Kroll made important contributions in this field. As Hertzberger (1991) emphasises, in structuralism one infills a structure with a long life-cycle with structures having shorter lifecycles. "Action space" and "discourse space" meet here. The architect's role is not to provide a complete solution, but to provide a spatial framework to be filled in eventually by the users. Following this direction, structuralism was sometimes coupled with phenomenology in the field of architectural theory. One of the major differences between these paradigms involves the status of the subject. From a structuralist perspective, the subject is construed as an effect of the signifying system; deep structures are valued over surface phenomena. This view is partly shared by Marx and Freud, both of whom were concerned with underlying causes and unconscious motivations, shifting the focus away from individual human consciousness and choice. Therefore, like Marxism and psychoanalysis, structuralism supports the ongoing modern diminishment of the self, considering the individual largely as a construct and consequence of impersonal systems. Individuals are able to initiate or control the codes and conventions of their social existence, mental life, or linguistic experience only to a very limited extent. As a consequence of this "demotion of the subject," structuralism has been widely criticised as an anti-humanistic perspective. Furthermore, structuralism excludes from consideration some important phenomena, such as history, which is treated merely as a passage from one state of the system to another.

\section{Critical theory}

\section{Basic characteristics}

Critical theory is a modern expression of Marxism - a materialistic, deterministic framework, closely incorporating science in its world view. Yet, the Marxist understanding of science is not value-free; on the contrary, it puts science "in practice at the service of the community" (Berndal, 1937, as cited in Willis et al., 2007, p. 27). The impact of Marxism in the domain of the social sciences was mainly through its derivation known as "historical materialism." In this view, changes in human and social behaviour across history are caused by material objects and the efforts of various social groups to obtain material goods at the expense of other groups. Furthermore, Marxism holds that if we are to understand a given phenomenon, we have to understand the context in which it operated.

Marxism emerged in the $19^{\text {th }}$ century, in the context of rapid industrialisation, as a response to the miserable conditions of factory workers. In The Communist Manifesto (1848), Marx and Engels conceptualise the history of all hitherto existing society as the history of class struggles. The conflict between classes in society is unavoidable. However, if it remains unresolved it will lead to the destruction of all classes. As those who have power are normally 
unwilling to give it up, the most likely way to improve the situation is, in the Marxist view, a revolution. Only in this way can those who are oppressed (the working class) free themselves from the oppression (created by the capitalists), and place the productive capacities of society into collective ownership. Upon this foundation, classes would be eradicated and the material basis for all forms of inequality between humankind would disperse.

According to Surber (1998), the main differences between traditional Marxism and critical theory are as follows:

- Critical theory assumes greater individual autonomy than traditional Marxism and rejects historical determinism.

- It does not place empirical social science in the "ideological superstructure" but sees it as a potential agent for social change and individual autonomy.

- Critical theorists primarily see themselves and like-minded intellectuals as the agents of change (since the proletariat did not succeed in changing the power structures). "Metaphorically, the critical theorist is a 'liberator' seeking through dialogue to make social actors aware of oppressive structures" (Murray \& Ozanne, 1991, p. 136).

- It takes into account the profound and pervasive influence of mass culture, in particular through the mass media (Surber, 1998, pp. 133-134).

Critical theory refers to a number of movements, but its foundations were established in the 1920s by the Frankfurt School, a group of scholars associated with the Institute of Social Research at the University of Frankfurt. Among the most prominent members of the group were Theodor Adorno, Max Horkheimer, Erich Fromm and Herbert Marcuse. The Frankfurt School expanded the focus of classical Marxism beyond the issues of industrial production and workerscapitalist struggle to include many other phenomena defining society, e.g., consumerism or mass media, which were seen as tools helping the ruling class to control the masses (by shaping the consciousness of individuals in a convenient way, e.g., justifying the status quo). Contemporary expressions of critical theory in the social sciences focus on oppression, marginalisation and social injustice based on such factors as gender, race, nationality, ethnicity, social class, etc. The advocates of critical theory maintain that even the ostensibly neutral formulations of science are to a large extent shaped by power struggles (Willis et al., 2007, pp. 45-48).

On the ontological level, the critical theory paradigm can be defined as "historical realism," i.e., reality is material and external to the human mind, but it is not possible to access it in an objective way (Willis et al., 2007, pp. 83-85). The reality accessible to the human mind is inherently shaped by social, political, cultural, gender values, etc., and these factors over the course of centuries "crystallised" or "reified" into a series of structures, which are inappropriately taken as "real," i.e., natural and immutable (Guba \& Lincoln, 1994, p. 110).

On the epistemological level, it is believed that truth statements are culturally, socially and historically mediated; they are not privileged in any absolute sense. The observer and the observed object are interactively linked; the values of the researchers influence the research findings. The task of the research is to uncover local instances of universal power structures and empower the oppressed (Willis et al., 2007, pp. 83-85). The starting point of inquiry is an ideological position, a conviction that the social relationships are entirely shaped by power factors.

On the methodological level, a dialectical dialogue between the inquirer and the subject of inquiry is seen as one of the research strategies; dialogue transforms misinterpretations and ignorance into a more informed consciousness (Guba \& Lincoln, 1994, p. 110). Research is considered a potential agent for social change and individual autonomy. Marx famously stated 
that "Philosophers have only interpreted the world in various ways; the point is to change it" (1845, Thesis XI). Because of the ideological foundation of the critical theory paradigm, research methods are not strictly limited; both qualitative and quantitative methods are acceptable.

\section{Influence on architectural discourse}

Critical theory was introduced to architectural discourse by Manfredo Tafuri and the School of Venice. Different aspects of critical thought are present in the writings of such scholars as Giancarlo De Carlo, Kenneth Frampton, Diane Ghirardo, Michael Hays, Peter Eisenman and Bernard Tschumi. There is also a growing body of feminist and postcolonial critiques of architecture within this paradigm. Commonly, critical theory in architectural discourse is coupled with elements of the constructivist framework.

Manfredo Tafuri is a key figure in critical theory of architecture and represents one of the most radical views in regards to the social potential of architecture; therefore his position deserves an introduction at this point. Tafuri's standpoint is built on a Marxist suspicion of ideologies (systems of legitimising and naturalising beliefs), which are construed in order to mask the profit-driven operation of capitalism. As Tafuri points out:

It is significant that almost all the economic objectives formulated by Keynes in his General Theory can be found, in purely ideological form, at the basis of the poetics of modern architecture. [...] The crisis of modern architecture begins at the precise moment when its natural target - large industrial capital - makes architecture's underlying ideology its own. (Tafuri, 1969, p. 29)

In the Marxist view, even the most ambitious and critical trends of independent culture are finally being assimilated by commercial culture, serving modern capitalism. According to Tafuri, this is the reason why a truly critical architecture or art is not possible, but there can only be a "class" critique of architecture. He states that "it is useless to struggle when one is trapped inside a capsule with no exit" (1969, p. 32). Ideological interventions may only cover the unbreakable alliance between the techniques of visual communication and commercial production; "there exists, between the avant-gardes of capital and the intellectual avant-gardes, a kind of tacit understanding, so tacit indeed that any attempt to bring it into the light elicits a chorus of indignant protest" (Tafuri, 1969, as cited in Hays, 1998, p. 6). Modern architecture finally marked the path of its destiny when it defined itself in terms of progress and rationalisation these ideals in fact are primarily serving the interests of capital.

Tafuri's extremely sceptical position with regards to the critical potential of architecture led him to define the primary task of architectural theory as "ideological criticism", the aim of which is to uncover and demystify the realities that lie behind such categories as architecture, art, city and to demystify "impotent and ineffectual myths," which often serve as illusions that permit the survival of anachronistic "hopes in design" (Tafuri, 1976, p. 182). The role of architects in Tafuri's view should be limited to clearly defined technical or administrative tasks.

What is of interest here is the precise identification of those tasks which capitalism development has taken away from architecture. [...] With this, one is led almost automatically to the discovery of what may well be the "drama" of architecture today: that is to see architecture obliged to return to pure architecture, to form without utopia; in the best cases, to sublime uselessness. To the deceptive attempts to give architecture an ideological dress, I shall always prefer the sincerity of those who have the courage to speak of that silent and outdated "purity"; even if this, too, still harbors an ideological inspiration, pathetic in its anachronism. (Tafuri, 1976, p. ix) 
Not surprisingly, many theoreticians find Tafuri's view difficult to accept, suggesting that the proposed limits would lead to the death of architecture, rather than to the solution of its problems. Following Tafuri's line of thinking, one could easily justify architecture's retreat from any social engagement and its move towards formalism, which is, for instance, advocated by Peter Eisenman, who explicitly professes his disinterest in political or social aspects of architecture (1984). Let us look at his polemic against the classical and humanist paradigms in architecture in his essay "The End of the Classical: the End of the Beginning, the End of the End" (1984), which has served as a canon text for many architectural students and architects:

What is being proposed is an expansion beyond the limitations presented by the classical model to the realization of architecture as an independent discourse, free of external values - classical or any other; that is, the intersection of the meaning-free, the arbitrary, and the timeless in the artificial. [...] A "not-classical" architecture is no longer a certification of an experience or a simulation of history, reason or reality in the present. Instead, it may more appropriately be described as an other manifestation, an architecture as is, now as a fiction. It is a representation of itself, of its own values and internal experience. (Eisenman, 1984, pp. 166-167)

Hays, owing much to Adorno, is less negative in his conclusions. Adorno believes in the critical potential of a work of art; in his view aesthetic experience can help us to resist the hegemony of instrumental rationality and the dominance of commerce. An autonomous work of art (in contrast to "affirmative," commercial art) awakens a reflexive, critical attitude towards the reality. Referring to Adorno, Hays in his essay "Critical Architecture: Between Culture and Form" (1984) argues for an architectural meaning that lies neither in the mass culture, nor in a "silent" form, but in the mediating space between these two. Refusing the view that contemporary architecture must choose between cultural dependence and formal autonomy, he states that architecture should be "resistant to the self-confirming, conciliatory operations of a dominant culture and yet irreducible to a purely formal structure disengaged from the contingencies of place and time" (Hays, 1984, p. 15). This kind of architecture can be named "critical."

Unlike Eisenman, Hays emphasises the importance of the relation between architectural objects and the socio-historical context of architectural production. What is problematic with his perspective, as well as with the positions more directly following Tafuri, is the implicit presumption that the architect can engage critically with contemporary problems solely through formal manipulation. As Ghirardo (1991) remarks, this premise has led to a contemporary version of Venturi's playful response to such problems as mass consumerism and commodification of culture.

Following Venturi's lead, architecture came to be seen as the silent witness to all of the weaknesses, indulgences, and self-absorption characteristic of modern culture. As disengaged voyeur, architecture first and foremost came to be understood as an exercise in meaning, meaning that issued from architect and emerged in the architecture [...] in the form of witty comment upon earlier conventions [...] or what is held to be comment upon a current social situation. (Ghirardo, 1991, pp. 9-10)

Tafuri, Eisenman, and Hays certainly do not exhaust the modalities of "criticality" within architectural theory, but due to their influence on architectural education during recent decades, they are most often associated with this position. De Carlo's (1969) emphasis on the value of user participation and his commitment to the resistance against consumer society (shared by such theorists as Frampton and Ghirardo) add an important dimension to the critical discourse in 
architecture. Nevertheless, these positions have not been as widely debated and appreciated as the aesthetic interpretations of criticality - perhaps due to their lack of a wider representation in architectural circles and a lesser ability to attract media attention.

\section{Postcriticality discussion}

In discussing critical theory in architecture, it is worthwhile to introduce a trend that emerged in opposition to this framework. One of the most important architectural debates of recent years has been going on between the proponents of the critical approach and those who think that the critical project is exhausted and has to be replaced by a "post-critical," "projective" practice. The main argument made by the advocates of this perspective is that the critical approach is of no relevance to the everyday design practice of architects.

A generation of people in their forties believes that criticism isn't a starting point for architecture at all, that criticism is a Marxist mistake, and that the idea of reflection should be replaced by a practice of 'projection.' (Van den Heuvel, 2006, para 2)

This debate is essentially about the role of architectural theory and the place of architecture in a wider social and cultural context. In their widely referred-to paper "Notes around the Doppler Effect and Other Moods of Modernism" (2002), Robert Somol and Sarah Whiting define their aim as follows:

As an alternative to the critical project - here linked to the indexical, the dialectical and hot representation $^{2}$ - this text develops an alternative genealogy of the projective - linked to the diagrammatic, the atmospheric and cool performance. (Somol \& Whiting, 2002, p. 74)

Somol and Whiting propose a move towards a "projective" architecture that, rather than resisting commercialisation, looks for opportunities within the capitalist society and exploits these. Postcritical theorists claim that "criticality" results in an architecture of stunted creativity and retrogression. They suggest that architecture should investigate intelligence, projection and innovation, seemingly staying away from a fruitless social critique and following the "creativity of the marketplace." It should perform in a manner that accelerates the discipline and refuses to look back for critiques. Efficacy, performativity and pragmatism are key issues here; however, it is claimed that "projective" architecture is not merely a turn to affirmative and "easy" commercial values, but it also aims to find a new approach that can both accommodate the complexity of the contemporary situation, as well as take a position toward it. "Projective" architecture primarily focuses on its own discipline instead of looking for legitimatisation of its practice in disciplines outside itself, like philosophy and the social sciences. It relies on "intelligent" problem-solving instead of intellectualised critique as a means of advancing the field.

No longer dictated by ideas or ideologies nor dependent on whether something is really true, everything now depends on credible intelligence, on whether something might be true. In architecture as in other fields we have witnessed a shift in intellectual dominance from philosophy and its search for absolute truth, to theory and its retreat into the "truth" of negative critique. (Speaks, 2002, p. 12)

Somol and Whiting hold up Rem Koolhaas as one of the earliest representatives of this new paradigm. Koolhaas has not been concerning himself with negative or analytical critique, but 
instead has been proposing an architecture that addresses the constantly changing world, in the hope of discovering new formal and cultural possibilities within the given settings. Already in the 1970s, Koolhaas referred to emerging issues such as American mass consumerism in an affirmative way, seeking for a "projective" architecture of new forms, events and behaviour. In one of his most influential works, $S, M, L, X L$ (Koolhaas \& Mau, 1995), he refers to the Attila Kotányi and Raoul Vaneigem (1961) situationist ${ }^{3}$ manifesto:

Architecture does really exist, like Coca-Cola: though coated with ideology, it is a real production, falsely satisfying a falsified need. Urbanism is comparable to the advertising propagated around Coca-Cola - pure spectacular ideology. (Kotányi \& Vaneigem, 1961, para 1)

Yet, unlike Kotányi and Vaneigem, Koolhaas argues that such a view of architecture is not likely to produce less hospitable environments. "People can inhabit anything. And they can be miserable in anything and ecstatic in anything. More and more I think that architecture has nothing to do with it" (Koolhaas, as cited in Heron, 1996, para 7). According to Koolhaas, the best architects can do is to get rid of a nostalgic view of architecture and follow the direction indicated by globalisation processes. For him, the erosion of identity in urban landscapes around the world is not a negative phenomenon. On the contrary, this "blankness" is a condition for freedom, for identity "imprisons," and resists expansion, interpretation, and renewal. In the rapid development of generic landscapes we are thus, according to Koolhaas, witnessing a "global liberation movement"4 (Koolhaas \& Mau, 1995, p. 1248). In Conversations with Students (1996), Koolhaas states:

I think we are stuck with this idea of the street and the plaza as public domain, but the public domain is radically changing [...] with television and the media and a whole series of other inventions, you could say that the public domain is lost. But you could also say that it's now so pervasive it does not need physical articulation any more. I think the truth is somewhere in between. But we as architects still look at it in terms of a nostalgic model, and in an incredibly moralistic sense, refuse signs of its being reinvented in other populist or more commercial terms. (Koolhaas, 1996, p. 45)

Koolhaas' view has a pessimistic undertone, perhaps contrary to his intentions. Is architecture so socially and culturally insignificant that there should be no other criteria for architectural choices than the commercial success? From this perspective, architecture becomes just one of the products of the market, which are essentially being designed to provide a quick profit. Yet, the life-span of architectural artefacts is much longer than any market trends or fashions. The following words of H. S. Thayer, although referring to philosophy and art, seem also relevant in relation to architecture:

In matters of intelligence and art, fashions are less to be trusted than feared. Few virtues and many vices may be fashionable. One difference between good and bad philosophic thought is that the former has a way of enduring in pertinence and effect, despite fashions, while the latter if not fashionable is nothing. (Thayer, as cited in Rosenthal \& Bourgeois, 1980, p. 5)

The representatives of attacked "criticality" do not seem to see a real threat in a "post-critical" stance. Hays maintained that the "post-critical" standpoint is only a rhetorical figure. In his view, critical theory is designed in such a way that it must constantly update itself; it must continually consider its own historicity. In contrast, many "after-theory" positions have neglected their own 
historical determinations, contexts and forms of authority. Moreover, the abandonment of the categories of ideology and resistance only insures the perpetuation of an ideology that does not label itself as such. There always has to be a provisional ground of ideology from which "to project" new possibilities.

The postcritical stance, with its emphasis on technology and progress as well as its simultaneous neglect of the local contexts of design, appears to be related to positivist/postpositivist ways of thinking. Yet it lacks the social agenda of the Modern Movement. As Hays argues, "projective intention" may be seen as a form of the neo-avant-garde impulse that, unlike earlier avant-gardes, is essentially "consumerist and complicit in its abandonment of critique and commitment; it is also managerial and instrumentalist in its blank and reified technologism" (Hays, 2007, para 4).

\section{Implications for user involvement}

One of the major aims of Marxism-inspired movements is to empower the disadvantaged segments of the society. Following from this, critical theory (understood in a non-reductive way) gives users of architecture a more prominent position than positivism. Yet, the starting point of inquiry is a conviction that the social relationships are entirely shaped by power factors. From this perspective, subjectivity is a product of historical and social processes. Critical theory thus represents a deterministic view of an individual and society. As Willis et al. (2007) observe, the researchers within this paradigm "know that power relationships are critical factors in society, and they know the research they conduct will find specific examples of the negative influence of those relationships" (p. 85). Furthermore, critical theorists primarily see themselves and likeminded intellectuals as the agents of change in the society. Users are rarely allowed to speak for themselves, since it is assumed that the theorist alone can evaluate their motivations and aims.

What should be emphasised is that critical theory in architecture has had its dominant influence in a specific, "negative" form, emerging from writings of Tafuri and further developed by Eisenman and Hays. The representatives of this trend assume that the pursuit of a "critical" architecture on a formal level is somehow equivalent to a critique of architecture's collaboration with the external forces it appears to resist. In other words, the hidden supposition here is that there exists an equivalence between a political critique and an aesthetic critique (Martin, 2005). The aesthetic appropriations of critical theory in architecture definitely do not encourage a user involvement. Furthermore, the interpretation of critical theory solely in aesthetic terms is a form of reductionism and it may indeed arouse doubts as to the utility and vitality of this perspective. This is definitely not a typical position for critical thought, for one of the major interests of Marxism-inspired movements is the historical and social context of investigated phenomena. Essentially ethical issues - such as the erosion of ignorance and transformative power of theory are among the main quality criteria.

In conclusion, architectural discourse still has much to learn from critical theory in the matter of user involvement. If the discourse is to be productive, however, architecture should be understood as an intervention into an environment that bears social, economic and political programs, and that in turn affects all of these domains, not as "self-expression and some form of effete cultural commentary" (Ghirardo, 1991, p. 10).

\section{Constructivism \\ Basic characteristics}

Constructivism emphasises the historicity, context-dependence, and socio-linguistically constituted character of all human activity. It may be seen as a reaction to a certain "crisis" which 
emerged in relation to:

- the failure of logical positivism as a philosophy of science;

- the impact of such works as Kuhn's The Structure of Scientific Revolutions (1962); Wittgenstein's Philosophical Investigations (1953); Feyerabend's Against Method (1975), Austin's How to do Things with Words (1962) and Bergen and Luckmann's The Social Construction of Reality (1966);

- $\quad$ an increase in the perceived relevance of both Continental and linguistic philosophy;

- contributions from philosophers such as Derrida, Rorty and Foucault (Hibberd, 2005, p. vii).

Constructivists hold that realities are apprehendable in the form of multiple mental constructions, socially- and experientially-based, local and specific in nature, although often shared among many individuals (Guba \& Lincoln, 1994, p. 110). One of the central points of this theory is that truth can never be claimed for the knowledge (or any piece of it) that human reason produces. In other words, the constructions are beyond the assertion of any existential, scientific, philosophical, or religious truth. From this perspective, knowledge (including scientific knowledge) is constructed by researchers and not discovered from the world. "The investigator and the object of investigation are assumed to be interactively linked so that the 'findings' are literally created as the investigation proceeds" (Guba \& Lincoln, 1994, p. 111).

Constructivists acknowledge that there may be an external world that is separate from the human mind and not dependent on it, but there is no possibility to come into direct contact with that reality (Every, 1998). From this perspective, our sign systems (language and other media) play a major part in "the social construction of reality" and realities cannot be separated from the sign systems in which they are experienced and interpreted. The other paradigms (with the exception of positivism) also acknowledge that even in relation to "physical reality," the social processes of mediation are involved, but they would certainly not agree that knowledge is barely a construct of the human mind. Yet, constructivists differ from extreme subjectivists in insisting that realities are not limitless and unique to the individual experience and interpretation; rather, they are the product of social negotiations and as such are far from being neutral in status.

Ontologically, constructivism can be characterised as relativism. Realities are defined as multiple, intangible mental constructions, socially and experientially grounded, local and specific in nature (however, with shared elements) and dependent for their form and content on the individual persons or groups holding the constructions. Constructions cannot be characterised as more or less true or correct in any absolute sense, but simply more or less informed and/or sophisticated (Guba \& Lincoln, 1994).

Epistemologically, constructivism can be described as "transactional and subjectivist." The investigator and the object of investigation are assumed to be interactively linked so that the "findings" are literally created during the research process (Guba \& Lincoln, 1994). Because in the constructivist view the world is a construction, one can adopt the constructivist principles only as working hypotheses that may or may not turn out to be viable. This is the main reason why the constructivist orientation is sometimes labelled as post-epistemological (Von Glasersfeld, 1990).

Methodologically, the variable and personal nature of social constructions implies that individual constructions can be elicited and refined only through interaction between an investigator and respondents. These constructions are often interpreted using conventional hermeneutical techniques and are compared and contrasted through a dialectical interchange. The final aim is to reach a "consensus construction" that is more informed and sophisticated than any 
of the hitherto existing constructions. Constructivist methodology is characterised by Guba and Lincoln (1994) as "hermeneutical and dialectical."

Langdon Winner, in his paper "Upon Opening the Black Box and Finding it Empty: Social Constructivism and the Philosophy of Technology" (1993), conducts a critical analysis of the constructivist approach. Admitting that there are many valuable aspects, such as a concern for specifics, and an attempt to provide accurate empirical models of investigated phenomena, Winner however states:

I am increasingly struck by the narrowness of this perspective. Advances along this line of inquiry take place at significant cost: a willingness to disregard important questions about technology and human experience, questions very much alive in other approaches. (Winner, 1993, pp. 367-368)

Examining examples of constructivist research on technology Winner points to numerous shortcomings such as:

- an almost total disregard for the social consequences of technological choice;

- a lack of reflectivity in defining "relevant" and "irrelevant" social actors and interest groups;

- a disregard for the possibility that in the studied phenomena, there may be a dynamics exceeding the processes revealed by studying the immediate needs, problems, interests and interactions of specific social actors (e.g., underlying conditions such as social class in Marx's theory);

- a lack of (and even apparent disdain for) any evaluative stance, not to mention moral or political principles, which would help to evaluate the consequences of studied phenomena (Winner, 1993, pp. 371-372).

As Winner concludes:

[...] the methodological bracketing of questions about interests and interpretations amounts to a political stance that regards the status quo and its ills and injustices with precision equanimity. Interpretive flexibility soon becomes moral and political indifference. (Winner, 1993, p. 372)

Constructivists show us "the fascinating dynamics of conflict, disagreement and consensus formation that surrounds some choices of great importance. But as they survey the evidence, they offer no judgment on what it all means" (Winner, 1993, p. 375). This is because constructivism takes the concept of truth to be a socially constructed (consequently a socially relative) one.

Constructivism has also been criticised for its implicitly presupposed deterministic view of language, which significantly constrains the minds and use of words by members of societies. They are not just "constructed" by language in this view, but are literally "determined" by it. However, there seems to be a contradiction here: the advocate of constructivism is not similarly constrained. While other individuals are controlled by the dominant concepts of society, the constructivist theorist can transcend these concepts and see though them (this objection may also be related to critical theory). As Mariyani-Squire argues, in the constructivist discourse one finds a kind of bifurcation between the theorist and the non-theorist:

The theorist always plays the role of the constructor of discourses, while the non-theorist plays the role of the subject who is constructed in a quite deterministic fashion. [...] here the theorist, conceptually anyway, "plays God" with his/her subject (whatever or whoever that may be). In 
short, while it is often assumed that Social Constructivism implies flexibility and indeterminism, there is no logical reason why one cannot treat social constructions as fatalistic. (MariyaniSquire, 1999, pp. 97-125)

The problems of constructivism mentioned above may to some extent be attributed to deficiencies in the critical self-reflectivity of this position. Although constructivists often present appealing, suggestive accounts of the investigated problems, it seems that they tend to undervalue the role of a critical, historical examination of used concepts and notions. This results in quite common misuse of scientific terminology, as illustrated by Sokal and Bricmont in their Fashionable Nonsense: Postmodern Intellectuals' Abuse of Science (1998).

\section{Influence on architectural discourse}

The constructivist paradigm 5 in architectural theory can hardly be identified in a "pure," univocal form. Most often constructivism in its different variations (primarily represented by interpretative frameworks such as poststructuralism and deconstruction) is coupled with critical theory and reconsiderations of architectural modernism. This has been a dominant mode of thought within architectural theory for over three decades (Hays, 1998). This trend has been represented by many educational institutes and periodicals, as well as by the most celebrated architects, such as Peter Eisenman, Bernard Tschumi and Daniel Liebeskind. Eisenman's cooperation with Jacques Derrida was one of the main channels from a deconstructivist philosophy to architectural theory.

The following quotation from Tschumi's widely praised book Architecture and Disjunction (1994) may serve as an example of a deconstructivist approach within architectural theory (here, Tschumi refers to the idea behind the structures he built at Le Parc de la Villette in the 1980s):

In this analogy, the contemporary city and its many parts - here La Villette - are made to correspond with the dissociated elements of schizophrenia [...] The transference in architecture resembles the psychoanalytic situation [...] This fragmentary transference in madness is nothing but the production of an ephemeral regrouping of exploded or dissociated structures. (Tschumi, 1994, pp. 177-178)

Such a way of conceptualising architecture is common in constructivism-inspired theory texts. An emphasis on individual experience without any significant concern for the shared, public sphere (which in a constructivist view is not "real") leads to a socially and culturally detached vision of architecture. One of the problems emerging here can be expressed in terms of a contradiction between an idiosyncratic approach and the claims of the universal validity of the work. On the one hand, there is an assumption that a creative architecture should be based on individualistic interpretation, as original and unique as possible; on the other hand, architects expect that the result will be universally understood and appreciated. However, this problem appears not only in the context of architecture. Loose connections established between personal feelings and ideas of universal validity; the arbitrary nature of the relation between the sphere of experience and the sphere of concepts; diffusion into separate activities aiming to solve particular problems; these are some of the symptoms of the general fragmentation and discontinuity of modern culture (Vesely, 2004).

Nikos Salingaros is one of the most engaged critics of constructivist-related approaches in architecture, particularly of architectural deconstruction. He highlights the common practice of misusing scientific concepts and terminology in relation to architecture. A deep confusion is 
often created by the superficial and arbitrary application of certain terms (e.g., fractal, chaos theory) and using scientific jargon in front of a non-scientific audience. This is essentially the problem of a lack of respect for the reader.

Architects and architectural critics have become expertly adept at fancy wordplay, sounding impressive while promoting the deconstructivist style's unnatural qualities. This linguistic dance is used to justify a meaningless architecture of fashion. The problem is that criticizing an empty but flowery discourse is like shadow boxing with phantoms one can never win a debate against an opponent who creates an impressionistic cloud empty of tangible facts. (Salingaros, 2004, p. 204)

The lack of conceptual clarity and rigour seems to be the case for a considerable part of constructivism-inspired architectural writings. Furthermore, one can observe a tendency to mix art and research, and the formal, aesthetic aspects often dominate the subject of the research. "There is a fascination for the art source per se, and sometimes it seems that the more amazing and fanciful a method is, the better" (Dahlberg, Dahlberg \& Nystrom, 2008, p. 334). An extensive use of artistic means in order to communicate the research findings may have a disturbing effect - it tends to make the researcher and her audience "come too close to the experience" and lose "the positive distance that brings us closer to an understanding, that makes us see the "otherness"' (p. 335). In other words, getting too close to the inquired issue, we end up being too distant from its meaning.

\section{Implications for user involvement}

Critics see constructivism-inspired architectural theory as a purely formal exercise with little social significance and lack of respect for the user, e.g., Frampton finds it "elitist and detached, testifying to the self-alienation of an avant-garde without a cause" (1994, p. 313). Yet, constructivists often argue that constructivism is liberating, because it enables "oppressed," disadvantaged groups to reconstruct "the reality" in accordance with their own interests rather than according to the interests of dominant groups in society. It also compels people to respect the alternative worldviews of "oppressed" groups, because there is no possibility of judging them to be inferior to dominant worldviews. Thus, constructivism is being closely linked to such movements as multiculturalism, broadly conceived as "the project of giving proper credit to the contributions of cultures and communities whose achievements have been historically neglected or undervalued" (Boghossian \& Peacocke, 2000, p. 181).

Some scholars, however, point to the internal inconsistency present in seeing constructivism as a perspective supporting "the oppressed" (Sokal \& Bricmont, 1998; Boghossian \& Peacocke, 2000). Even though constructivism supplies a philosophical basis which helps to prevent anyone from accusing disadvantaged social groups or cultures of holding false or unjustified views, it is difficult to understand how this could be a good way to argue for their rights.

For if the powerful can't criticize the oppressed, because the central epistemological categories are inexorably tied to particular perspectives, it also follows that the oppressed can't criticize the powerful. The only remedy, so far as I can see, for what threatens to be a strongly conservative upshot, is to accept an overt double standard: allow a questionable idea to be criticized if it is held by those in a position of power - Christian creationism, for example - but not if it is held by those whom the powerful oppress - Zuni creationism, for example. Familiar as this stratagem has recently become, how can it possibly appeal to anyone with the slightest degree of intellectual 
integrity; and how can it fail to seem anything other than deeply offensive to the progressive sensibilities whose cause it is supposed to further? (Boghossian \& Peacocke, 2000, p. 181)

The central problem here is the lack of any foundational criteria of validity in the constructivist framework. As Guba and Lincoln admit, in a constructivist view there is no way to elevate one theory over another on the basis of any ultimate criteria. "No construction is or can be incontrovertibly right; advocates of any particular construction must rely on persuasiveness and utility rather than proof in arguing their position" (Guba \& Lincoln, 1994, p. 108). Accordingly, it seems that in this perspective, some social groups/individuals have a privileged position - those who are more likely to elaborate the most informed and sophisticated view, those who can be most persuasive and can convincingly demonstrate the utility of presented theories are in most cases those who are already in power, not the weaker segments of the society (in our case, the inhabitants). In this, constructivism may indirectly support the status quo, i.e., the existing power structures including the socially detached position of architects.

\section{Phenomenology}

\section{Basic characteristics}

Phenomenology in its etymological sense is the activity of giving an account (logos) of the way things appear (phainomenon). In other words, it is concerned with phenomena (anything that presents itself to consciousness) and aims to depict them directly as they appear. The definition given by Maurice Merleau-Ponty in the introduction to his Phenomenology of Perception (1945) gives a more specific idea about phenomenology:

$[\mathrm{P}]$ henomenology is a philosophy which $[\ldots]$ does not expect to arrive at an understanding of man and the world from any starting point other than of their "facticity". It is a [...] a philosophy for which the world is always "already there" before reflection begins - as an inalienable presence; and all its efforts are concentrated upon re-achieving a direct and primitive contact with the world, and endowing that contact with a philosophical status. It is the search for a philosophy which shall be a "rigorous science", but it also offers an account of space, time and the world as we "live" them. It tries to give a direct description of our experience as it is. (Merleau-Ponty, 2002, p. vii)

Phenomenology, developed at the time of the dominance of positivism, was an alternative, even ground-breaking way of looking at the world, in the sense that it was interested not in the objective properties of things; instead, it investigated how we relate to things in the real world.

Edmund Husserl is considered "the father of phenomenology". Phenomenology as a philosophical movement was initiated with his Logical Investigations (1900-1901). Husserl's phenomenology develops in the context of his critique of the dominant, objectifying, positivisminspired philosophical tendencies of his time. These currents, according to Husserl, are reducing philosophical knowledge to factual, scientific knowledge. For him, the main task of philosophy is to pursue and discover indubitable knowledge in contradistinction to factual knowledge that could never be apodictically certain.

The purpose of taking the phenomenological attitude is to return to "the things themselves," to go back to the world that is more basic than scientific conceptualisation. He argued that the problem of phenomenological inquiry is not that we know too little about the phenomenon we wish to investigate, but that we know too much. In other words, the problem is that our "common sense" suppositions and the existing body of scientific knowledge predispose us to interpret the nature of the phenomenon in a certain way. As long as we assume our everyday 
approach towards the world, it remains in a certain sense hidden. Thus, in order to go back to "the things themselves" we have to adopt a specific philosophical attitude. In this context, on the methodological level, Husserl advocates epoche, "phenomenological reduction," a sort of Cartesian doubt in regards to all beliefs dictated by common sense.

Husserl initially argued that a philosopher should put all beliefs, as well as knowledge regarding the natural-empirical world, in "brackets". Nevertheless, towards the end of his life, he became aware of the problems related to phenomenological reduction in its radical form. He admitted that even at the deepest level, consciousness is operating in the world of socially and culturally grounded meanings and pre-judgments. Other phenomenologists (e.g., Heidegger, Merleau-Ponty) insisted that epoche should not be thought of as a total withdrawal from the world into a kind of absolute subjectivity, but rather it consists of changing our way of seeing the world, "relearning to look at the world" (Merleau-Ponty, 2002, p. xxiii), in an attitude of "wonder" towards the world (Merleau-Ponty, 2002, p. xv). We do so when we make explicit our understandings, beliefs, and biases, and then try to temporarily abandon this conceptual framework. Referring to phenomenological reduction, Dahlberg et al. (2008) state that "Researchers have to find ways to scrutinise themselves in order to encounter data in an open manner; truly willing to be surprised and understand that one did not know after all" (p. 242).

Since the publication of Husserl's early works, phenomenology has developed significantly. One can distinguish a great number of different approaches, most of them however follow one of two major traditions - descriptive phenomenology (focused on the description of phenomena as they appear in human consciousness), referring primarily to the writings of Husserl, and hermeneutic (or interpretive) phenomenology, which emerged from the works of Heidegger.

While Husserl concentrated foremost on epistemology, in Heidegger's view, phenomenology went beyond the description of lived experience and aimed at its philosophical interpretation. Hermeneutic phenomenology emphasises our embeddedness in the world of language and social relationships and the historicity of all understanding.

As Heidegger (1927) emphasises, we always refer to things as being "within-the-world," and this indicates that we have an intuitive understanding of the world, as coming before the notion of the things that are present within it. We understand ourselves and things in terms of the world. The world, however, is not the ultimate frame within which everything is conceived; the world also needs a human existence to perceive it. Phenomenology thus concedes that the "world" is, in fact, also a part of Dasein, human existence. The human world is always a lived-world, a lifeworld.

Hans-Georg Gadamer was one of the most prominent continuators of the hermeneutic phenomenological tradition. In Truth and Method (1960) he reflects on the nature of understanding. He emphasises that the fact that we are situated within traditions does not mean that we are limited in our freedom. On the contrary, traditions - rather than limiting us - open us up to what is to be understood. They are an irreducible element of the human way of comprehending the world.

The horizon of the present cannot be formed without the past. There is no more an isolated horizon of the present itself than there are historical horizons which have to be acquired. Rather, understanding is always the fusion of these horizons supposedly existing by themselves. (Gadamer, 2004, p. 305)

The past unavoidably enters into a relation with the present life. It then follows that meaning is never complete; it is open to interpretations that may come from future perspectives. According 
to Gadamer, "Not just occasionally but always, the meaning of a text goes beyond its author. That is why understanding is not merely a reproductive but always a productive activity as well" (2004, p. 296).

Summing up, on the ontological level, phenomenology acknowledges the foundational character of the lifeworld (the human world, a world filled with meanings, values). The lifeworld is the ultimate horizon for all cognitive activities; as Husserl put it, "The concrete life-world [...] is the grounding soil of the 'scientifically true' world" (1970, p. 130).

The concept of lifeworld implies an epistemology in which the question of meaning is most important. Lived experience (a first-person experience of the world) is the primary source of knowledge, but non-intuitional (e.g., scientific) perspectives as a part of the lifeworld are also taken into account. Phenomenology is not in principle opposed to objectivist approaches (such as natural science) but it is in opposition to the views that consider scientific models as the only valid models, leaving no space for alternative perspectives.

Methodologically, depending on the approach adopted, phenomenologists focus either on a description of human experience as lived, or on the interpretation of its meanings. Nevertheless, some more contemporary scholars choose to see description and interpretation as a continuum where specific research may be more or less interpretative/descriptive, arguing that traditional boundaries "would be antithetical to the spirit of the phenomenological tradition that prizes individuality and creativity" (Langdridge, 2008, p. 1131).

The opponents of phenomenological hermeneutics often accuse it of being intrinsically conservative. One of the major criticisms has been formulated by Jürgen Habermas, who argued that seeing the tradition as a basis for understanding "shifts the balance between authority and reason" (1977, p. 268). The emphasis on tradition may indeed have a conservative resonance. Nevertheless, Gadamer resolutely protested against labelling hermeneutics conservative.

It is a grave misunderstanding to assume that emphasis on the essential factor of tradition which enters into all understanding implies an uncritical acceptance of tradition and sociopolitical conservatism [...] In truth the confrontation of our historic tradition is always a critical challenge of the tradition. (Gadamer, 1979, p. 108)

Considering the relational nature of human understanding, a total rejection of tradition is utopic. However, the impossibility of a total critique does not imply that there are things that cannot be criticised. According to Gadamer (1960), "the happening of tradition" or a fusion of horizons, admits to a kind of hermeneutic self-reflection on the part of language in dialogue with the authority of tradition. In other words, tradition - as viewed by hermeneutics - does not present an obstacle to critical reason. As Madison (2000) argues, hermeneutics could be rightly labelled as conservative if it held that all values are tradition-dependent (rejecting the universality of certain values). The belief in the "universality" of values is important, because by only appealing to values that are not relative to the tradition to which we belong are we able to elaborate a critique of this tradition. ${ }^{6}$

Furthermore, the phenomenological emphasis on tradition does not imply the incessant repetition of the same. "Tradition" in hermeneutic understanding is a "living" tradition, always mediated by our situatedness in a specific social and historical context. Accordingly, the same tradition should always be understood in a different way. What is commonly referred to as "traditional" (e.g., traditional societies, traditional building) and is characterised by a denial of any change ceases to represent tradition in a hermeneutic sense. 


\section{Influence on architectural theory}

The phenomenological line of thinking in architecture was initiated in 1951 with Heidegger's lecture "Building, Dwelling, Thinking". The lecture was presented to a group of leading architects in Darmstadt, during the symposium on "Man and Space". In this lecture, Heidegger questions the instrumental, pragmatic approach of the Modern Movement, and argues that the essential task of architecture is not solely appeasing the "hunger" of houses, but satisfying our deepest, existential needs, this means: to help us to grow as human beings; to "dwell". The activity of building helps us to gather elements of our lifeworld and concretise, embody them in our environment. In this, it provides meaningful settings for human existence. The famous example of a peasant cottage in the Black Forrest exemplifies building that emerges from the lifeworld of peasants and "houses" their dwelling.

Let us think for a while of a farmhouse in the Black Forest, which was built some two hundred years ago by the dwelling of peasants. [...] It placed the farm on the wind-sheltered mountain slope looking south, among the meadows close to the spring. It gave it the wide overhanging shingle roof whose proper slope bears up under the burden of snow, and which, reaching deep down, shields the chambers against the storms of the long winter nights. It did not forget the altar corner behind the community table; it made room in its chamber for the hallowed places of childbed and the "tree of the dead" - for that is what they call a coffin there: the Totenbaum - and in this way it designed for the different generations under one roof the character of their journey through time. A craft which, itself sprung from dwelling, still uses its tools and frames as things, built the farmhouse. (Heidegger, 1977, p. 338)

Contrary to what is sometimes being suggested by the critics of phenomenology, Heidegger is not calling here for a return to vernacular ways of building. His intention is far from providing stylistic suggestions. He explicitly states that his reference to the Black Forest farm in no way means that we should or could go back to building such houses. Rather, this example "illustrates by a dwelling that has been how it was able to build" (Heidegger, 1977, p. 338). Heidegger admits that this way of living no longer exists. The task for architects is not to repeat historical forms, but to find expressions for the current ways of "dwelling", meaningful expressions for the contemporary ways of life. This task is essentially the task of interpretation. There are no straightforward procedures to be followed by those who design and build, but personal effort and dedication are crucial. Tradition is important here, but it is not just what lies behind us and what we adopt more or less automatically. Rather, it is a task. From this perspective, our relation to tradition precludes passivity; instead it demands active questioning and self-questioning.

Hermeneutic phenomenological ideas in architecture have been further developed by such theorists as Christian Norberg-Schulz, Dalibor Vesely, Karsten Harries and Alberto PérezGómez. The common characteristic of phenomenology-inspired architectural theories is conceiving architecture as a part of the lifeworld, as a manifestation of our way of being in the world.

Christian Norberg-Schulz (1971) argues that the structure of architectural space should reflect our existential space, i.e., the way we relate to the world. Accordingly, a thorough consideration of users' lifeworld, their ways of being, and their perspectives should provide a point of departure for architectural discourse and design choices.

The meaning of a work of architecture [...] consists in its gathering the world in a general typical sense, in a local particular sense, in a temporal historical sense, and, finally, as something, that is, as the figural manifestation of a mode of dwelling between earth and sky. A work of architecture 
does not exist in a vacuum, but in the world of things and human beings, and reveals this world as what it is. (Norberg-Schulz, 1985, p. 30)

Following Heidegger, Norberg-Schulz emphasises that the role of architecture is to assist us in establishing a meaningful relation with the world, to help us to interpret and understand the world.

Alberto Pérez-Gómez (1983), referring to Husserl's The Crisis of European Sciences (1936), maintains that separation of architectural theory and practice originates in the modern transformations, i.e., conceptual shifts that took place after the beginning of the $19^{\text {th }}$ century. What were the consequences of these changes for architecture? Architectural theory - similarly to modern science - has been devoid of a reference to the lifeworld.

Because architectural theory is assumed to imply absolute rationality, it has been considered capable of standing on its own, free of all relations to fundamental philosophical questions. Subject to the values of technology, its interest is not in meaning, but in a conceptual or material efficiency dominating design and construction. This naturally has created a peculiar tension between theory and practice. Theory may work smoothly on a formal level, but it is unable to come to terms with reality. Correlatively, practice has been transformed into a process of production, without existential meaning, clearly defined aims, or reference to human values. Or else practice has ignored its connections to theory in order to recover its poetic dimension. (PérezGómez, 1983, p. 8)

Further, Pérez-Gómez adds:

The illusion remains, however, that practice can be reduced to a system of rational prescriptive rules. This is particularly evident in architectural education and obstructs our perception on how the relation between theory and practice operated until the end of the eighteenth century. (PérezGómez , 1983, p. 8)

As a result, architects fail to understand and acknowledge the transcendental dimension of meaning in architecture. Before the beginning of the $19^{\text {th }}$ century, architects never considered formal language as the sole source of meaning. Architectural form was not an autonomous invention, but an embodiment of a certain style of life, an expression of a specific culture. According to Pérez-Gómez, "Today architects often work under the absurd assumption that meaning and symbol are merely products of the mind, that they can be manufactured a priori and that they possess somehow the certainty of number" (1983, p. 12). Consequently, the gap between architectural theory and practice increases. This is closely related to the distance between technological/economic development and the lived world of human values and meanings.

Phenomenology provides us with an alternative in which human values and practical engagement with the world are primary to the scientific rationality. The basic assumptions of phenomenology - the foundational character of lived experience and the primordiality of the lifeworld - imply inseparable relation between theory and practice in any domain of human activity. Karsten Harries (1983) conducts a critique of modern aesthetics from a phenomenological perspective, referring specifically to architecture. The point of departure of his criticism is the problem of arbitrariness in contemporary architecture. Harries sees the "possibility of otherwiseness" as a characteristic linking diverse, contemporary architectural movements (Harries, 1983, as cited in Seamon, 1993, p. 43). The "aesthetic approach" dictated 
by the concepts of modern aesthetics is to be blamed for the problem. Its main consequence is a broken relation between architecture and the lifeworld.

The aesthetic approach - which for more than two centuries has dominated both reflection about art and artistic practice - has led to an architecture of decorated sheds. Given such an approach, the proper focus of aesthetic concern is in a deep sense never more than just decoration and shed cannot but strike us as arbitrary, no matter how much the decoration may present itself to us as a selfjustifying aesthetic presence - as arbitrary as the relation of a strong painting to the wall on which it happens to hang. (Harries, 1983, as cited in Seamon, 1993, pp. 43-44)

Harries emphasises that the concept of beauty represented by modern aesthetics is very limited; an important ethical dimension has been lost. He seeks a more profound basis for architectural design and finds it in phenomenology, particularly in Heidegger's ideas. In the phenomenological framework, there is no need for opposing ethical and aesthetic concerns. On the contrary, the concept of art and possible ethics are dimensions of the same phenomenon. A central issue for both is the reference to the conditions of our being-in-the-world. Dalibor Vesely (2004) shares this position, speaking about "emancipatory" and "participatory" modes of representation in art and architecture. The "emancipatory" mode of representation is the arbitrary, autonomous ideal of contemporary aesthetics. The "participatory" mode of representation refers to the Greek view of art; it is essentially grounded in the lifeworld and includes an ethical dimension.

In conclusion, for phenomenologists the central problem of contemporary architecture is the contradiction between the dominating aesthetic or instrumental approach, and "our inability to view buildings apart from any consideration of dwelling" (Harries, 1983, as cited in Seamon, 1993, p. 44). Architectural artefacts created with no deeper regard to human ways of being do not provide a meaningful context for their inhabitants. As Harries emphasises, the problem of arbitrariness in architecture is essentially a hermeneutical problem. It may be solved only to the extent that architects make the effort of understanding what human existence is to be. From this perspective, the major task of architecture is "to help to articulate common ethos" (Harries, 1997, p. 4). This is essentially the task of "the interpretation of the way of life valid for our period" (Giedion, 1974, p. xxxiii).

\section{Implications for user involvement}

What is the main strength of phenomenology in the argument for user involvement? According to the phenomenological perspective, lived experience is the foundation of rationality. Our "situatedness," our involvement in the lifeworld, is not an obstacle, but a proper condition for understanding. Human beings make sense of the world from within lived experience, not detached from it. Consequently, the "lay perspective" of the user gains a significant importance, and the disengaged, "expert knowledge" of an architect is not considered as a privileged form of rationality.

Yet, addressing users' lived experience in a non-reductive way is one of the challenges of phenomenology-inspired architectural practice. Getting direct feedback is often not enough. A way to get closer to inhabitants' perspectives is to combine different ways of getting their direct response with an empathetic consideration of the meanings of their lifeworld. These meanings may appear more clearly in a painting, a film, or a novel than in a direct survey of users' opinions. An interpretative effort is central here, particularly in situations where an architect is working in settings different from her lifeworld. 
Accentuating the foundational role of human experience, phenomenology avoids the subjectivism and relativism of the constructivist perspective. As Husserl indicates, the lifeworld, in all its relativity, possesses a "concrete universality," i.e., some general structures, the invariant elements shared by all diverse cultural worlds, irrespective of their being layered on cultural senses (Steinbock, 1995, p. 96). Such an invariable element is for instance the nature of understanding: we always understand in a historical context, the horizon of the present cannot be formed without our past (Gadamer, 1960). What follows is that while from the phenomenological perspective norms are context-independent, they are not for this reason simply relative or arbitrary. Thus, phenomenology enables us to engage in a rational, non-arbitrary critique of actually existing practices in different domains of human activity. As Madison (2001) remarks, phenomenological theory "enables us to come up with (universalizable) reasons why some practices are better than others" (Madison, 2001, p. 5).

\section{Summary}

This paper has discussed the major paradigms underpinning contemporary architectural discourse, explicating how different paradigms ground different approaches to users. The conducted analyses indicate that the dominant approaches within architectural theory tend to underestimate the value of the user's perspective.

Positivist/postpositivist frameworks concentrate primarily on quantitatively measurable phenomena; prioritise scientific, expert knowledge; and refrain from considering subjectivity. Structuralism, although it takes into account the dimension of meaning, to a large extent rejects the concept of human freedom and choice and focuses instead on the way that human behaviour is determined by various structures.

Critical perspectives, although they refer to participation (as a strategy of empowering the "oppressed" groups), are not interested as much in an individual perspective as they are in social processes. Individual autonomy and concreteness of an individual experience can be obscured by a generalising, ideologically grounded and deterministic model of social mechanisms. Furthermore, even though the understanding of critical theory within the human sciences suggests a close interaction of theory and practice, this framework tends to be appropriated in architecture in abstract, aesthetic terms. As a consequence, user-related concerns are further marginalised.

Constructivist frameworks acknowledge the importance of individual human experience, but deny the existence of a shared background other than a common interpretation. This rejection of universalism leads to relativism, incommensurability, moral particularism, ${ }^{7}$ and even nihilism (Harris, as cited in Madison, 2001, p. ix). Specifically in the field of architecture, constructivisminspired theories often promote a strictly individualistic, at times even explicitly anti-social, view of this discipline represented by their authors (e.g., Tschumi, 1994). However, this is in line with the main assumptions of constructivism - that the only criteria of validity for a given theory are its persuasiveness and sophistication (Guba \& Lincoln, 1994).

Phenomenology, beginning and extending from the perspective of lifeworld and lived experience, appears to be the most relevant framework supporting a user- and context-sensitive architectural practice. Lived experience is here the foundation of rationality; accordingly the "lay perspective" of the user gains a significant importance. Yet, the question of user involvement extends far beyond addressing the opinion of users. Respect towards the perspective of an individual here is inseparable from the appreciation of her lifeworld, the social and cultural context of architecture. Accordingly, the phenomenological framework does not imply that architects should abdicate their responsibility and simply follow the desires of users. This could easily lead to the view of architecture as a commodity. The task of the architect is rather to 
negotiate between the needs of the clients and more general objectives generated by a careful consideration of the context of the design. Therefore, a user-oriented architectural practice from the phenomenological perspective ultimately refers to architecture's participation in the culture.

\section{Beata Sirowy}

Postdoc, PhD

Norwegian University of Life Sciences, Department of Landscape and Spatial Planning

Email address: beata.sirowy@umb.no

\section{References}

Agrest, D. (1991). Architecture from Without: theoretical framings for a critical practice. Cambridge, MA: The MIT Press.

Alexander, C. (2004). The Interaction of Architecture and Science. Katarxis no 3: New Science, New Urbanism, New Architecture? [On-line]. Available: http://www.katarxis3.com/Alexander_Architecture_Science.htm Retrieved February 16, 2008.

Boghossian, P. \& Peacocke, C. (Eds.). (2000). New Essays on the A Priori. Oxford: Oxford University Press.

Dahlberg, K., Dahlberg, K. \& Nystrom, M. (2008). Reflective Lifeworld Research. Lund: Studentlitteratur.

Debord, G. (1967). The Society of the Spectacle. Available: http://www.bopsecrets.org/SI/debord/; translation by Ken Knabb (2002). Retrieved February 10, 2008.

De Carlo, G. (1969). Architecture's Public. In P. Jones, D. Petrescu, \& J. Till (Eds.), (2007), Architecture and Participation (pp. 3-22). Abingdon: Spon Press.

Eason, K. (1987). Information technology and organizational change. London: Taylor and Francis.

Eisenman, P. (1984). The End of the Classical: The End of the Beginning, the End of the End. Perspecta 21: The Yale Architectural Journal.

Every, P. (1998). Incommensurability, relativism, methodology. [On-line]. Available: http://www.csad.coventry.ac.uk/idn/neopraxis/psci.htm Retrieved February 16, 2009.

Frampton, K. (1994). Modern Architecture: A critical history. London: Thames and Hudson.

Franciscono, M. (1971). Walter Gropius and the creation of the Bauhaus in Weimar: the ideals and artistic theories of its founding years. Urbana: University of Illinois Press.

Gadamer, H. G. (1979) [1963]. The problem of historical consciousness. In P. Rabinow \& M. Sullivan, （Eds.), Interpretive social science: A reader (pp. 103-162) Berkeley: University of California Press.

Gadamer, H. G. (2004) [1960]. Truth and Method. London: Continuum.

Galison, P. (1990). Aufbau/Bauhaus: Logical positivism and architectural modernism. Critical Inquiry 16, 709-52.

Ghirardo, D. (1991). Out of Site: A Social Criticism of Architecture. Seattle: Bay Press.

Giedion, S. (1974). Space, Time and Architecture. Cambridge, MA: Harvard University Press.

Guba, E. \& Lincoln, Y. (1994). Competing paradigms in qualitative research. In N. Denzin \& Y. Lincoln, (Eds.), Handbook of qualitative research (pp. 105-117). Thousand Oaks: Sage.

Habermas, J. (1977). A review of Gadamer's Truth and Method. In B. Wachterhauser, (Ed.), (1986), Hermeneutics and Modern Philosophy (pp. 243-276). Albany, NY: State University of New York Press.

Harries, K. (1983). Thoughts on a Non-Arbitrary Architecture. In D. Seamon, (Ed.), (1993), Dwelling, Seeing, and Designing: Toward a Phenomenological Ecology (pp. 41-59). Albany, NY: State University of New York Press. 
Beata Sirowy Among paradigms: Major ways of framing user-related problems in contemporary architectural discourse

Harries, K. (1997). The Ethical Function of Architecture. Cambridge, MA: The MIT Press.

Hays, K. M. (1984). Critical Architecture: Between Culture and Form. Perspecta 21: The Yale Architectural Journal, 14-29.

Hays, K. M. (Ed.). (1998). Architecture theory since 1968. Cambridge, MA: The MIT Press.

Hays, K. M. (2007). Michael Hays in conversation with Izabel Gass on postcriticality. Manifold Magazine. [Online]. Available: http://www.manifoldmagazine.com/index.php/2007/05/06/k-michael-hays Retrieved February 22, 2009.

Heidegger, M. (1962) [1927]. Being and Time. NY: Harper \& Row.

Heidegger, M. (1977) [1951]. Building, Dwelling, Thinking. In Martin Heidegger: Basic Writings (pp. 319-340). London: Routledge.

Heron, K. (1996). From Bauhaus to Koolhaas. An interview with Rem Koolhaas. Wired, 4.07. [On-line]. Available: www.wired.com/wired/archive/4.07/koolhaas.html Retrieved March 18, 2007.

Hertzberger, H. (1991). Lessons for Students in Architecture. Rotterdam: Uitgeverij Publishers.

Hibberd, F. (2005). Unfolding Social Constructionism. Boston, MA: Springer Science + Business Media, Inc.

Husserl, E. (1970) [1936]. The Crisis of European Sciences and Transcendental Phenomenology. Evaston, IL: North Western University Press.

Jencks, C. \& Kropf, K. (Eds.). (1997). Theories and Manifestoes of Contemporary Architecture. Chichester: Academy Editions.

Johnson, P. A. (1994). The Theory of Architecture. NY: Van Nostrand Reinhold.

Koolhaas, R. \& Mau, B. (1995). S, M, L, XL. NY: Monacelli Press.

Koolhaas, R. (1996). Conversations with students. NY: Princeton Architectural Press.

Kotányi, A. \& Vaneigem, R. (1961). Basic Program of the Bureau of Unitary Urbanism. Available: http://www.bopsecrets.org/SI/6.unitaryurb.htm\#N_1 Retrieved February 16, 2009.

Langdridge, D. (2008). Phenomenology and critical social psychology: Directions and debates in theory and research. Social and Personality Psychology Compass, 2(3), 1126-1142.

Lavin, S. (Ed.). (2005). Crib Sheets: Notes on the Contemporary Architectural Conversation. NY: Monacelli Press.

Madison, G. B. (2000). Is Hermeneutics Necessarily Conservative? Symposium. Journal of the Canadian Society for Hermeneutics and Postmodern Thought. [On-line]. Available: http://www.ualberta.ca/ di/csh/csh10/Madison.html Retrieved May 16, 2008.

Madison, G. B. (2001). The Politics of Postmodernity: Essays in Applied Hermeneutics. Dodrecht: Kluwer Academic Publishers.

Mariyani-Squire, E. (1999). Social Constructivism: A flawed debate over conceptual foundations. Capitalism, Nature, Socialism, 10(4), 97-125.

Martin, R. (2005). Critical of What? Toward a Utopian Realism. Harvard Design Magazine, Number 22. Available: http://www.gsd.harvard.edu/research/publications/hdm/back/22 OnTheory.html Retrieved January 18, 2009.

Marx, K. (1845). Theses on Feuerbach. Available: http://www.marxists.org/archive/marx/works/1845/theses/theses.htm

Marx, K. \& Engels, F. (1848). The Communist Manifesto. Available: http://www.marxists.org/archive/marx/works/1848/communist-manifesto/

Merleau-Ponty, M. (2002) [1945]. Phenomenology of Perception. London: Routledge.

Murray, J. B. \& Ozanne, J. (1991). The Critical Imagination: Emancipatory Interests in Consumer Research. Journal of Consumer Research, 18, 129-144. 
Beata Sirowy Among paradigms: Major ways of framing user-related problems in contemporary architectural discourse

Nesbitt, K. (Ed.). (1996). Theorizing a New Agenda for Architecture: an anthology of architectural theory. NY: Princeton Architectural Press.

Norberg-Schulz, C. (1971). Existence, Space, Architecture. London: Studio Vista.

Norberg-Schulz, Ch. (1985). The Concept of Dwelling. On the way to figurative architecture. NY: Rizzoli.

Osborne, H. (1979). Abstraction and Artifice in Twentieth-Century Art. Oxford: Clarendon Press.

Pérez-Gómez, A. (1983). Architecture and the Crisis of Modern Science. Cambridge, MA: The MIT Press.

Rosenthal, S. \& Bourgeois, P. (1980). Pragmatism and phenomenology: A philosophic encounter. Amsterdam: B. R. Grüner.

Salingaros, N. (2004). Anti-Architecture and Deconstruction. Solingen: Umbau-Verlag.

Schön, D. (1991) [1983]. The Reflective Practitioner. NY: Basic Books.

Sirowy, B. (2010). Phenomenological Concepts in Architecture. Towards a User-Oriented Practice. A PhD dissertation. Oslo: Oslo School of Architecture and Design.

Sokal, A. \& Bricmont, J. (1998). Fashionable Nonsense: Postmodern Intellectuals'Abuse of Science. London: Profile Books.

Somol, R. \& Whiting, S. (2002). Notes around the Doppler Effect and Other Moods of Modernism. Perspecta 33: The Yale Architectural Journal.

Speaks, M. (2002). Design Intelligence, Part I: Introduction. A + U, December, 10-18.

Steinbock, A. (1995). Home and Beyond: Generative Phenomenology after Husserl. Evanston, IL: Northwestern University Press.

Stevens, G. (1998). The Favored Circle: The Social Foundations of Architectural Distinction. Cambridge, MA: The MIT Press.

Surber, J. P. (1998). Culture and Critique: An Introduction to the Critical Discourses of Cultural Studies. Boulder, CO: Westview Press.

Tafuri, M. (1969). Toward a Critique of Architectural Ideology. In K. M. Hays (Ed.), (1998), Architecture Theory since 1968. Cambridge, MA: The MIT Press.

Tafuri, M. (1976). Architecture and Utopia: Design and Capitalist Development. Cambridge, MA: The MIT Press.

Tschumi, B. (1994). Architecture and Disjunction. Cambridge, MA: The MIT Press.

Van den Heuvel, D. (2006). The Projective Bubble. ArchiNed. 30.03. [On-line]. Available: http://www.archined.nl/archined/5315.html Retrieved January 22, 2008.

Vesely, D. (2004). Architecture in the Age of Divided Representation: The Question of Creativity in the Shadow of Production. Cambridge, MA: The MIT Press.

Von Glasersfeld, E. (1990). An exposition of constructivism: Why some like it radical. In R. B. Davis, C. A. Maher, \& N. Noddings, (Eds.), Monographs of the Journal for Research in Mathematics Education, \#4 (pp. 19-29). Reston, VA: National Council of Teachers of Mathematics.

Willis, J., Jost, M., \& Nilakanta, R. (2007). Foundations of Qualitative Research: Interpretive and critical approaches. Thousand Oaks, CA: Sage Publications.

Winner, L. (1993). Upon Opening the Black Box and Finding it Empty: Social Constructivism and the Philosophy of Technology. In J. Pitt \& E. Lugo, (Eds.), The Technology of Discovery and the Discovery of Technology. Blacksburg, VA: Society for Philosophy and Technology.

Wittgenstein. L. (1953) [2001]. Philosophical Investigations. Malden, MA: Blackwell Publishing.

Yanchar, S. C. \& Hill, J. R. (2003). What is psychology about? Toward an explicit ontology. Journal of Humanistic Psychology, 43(1), 11-32. 


\section{Endnotes}

${ }^{1}$ Structuralism also has some common points e.g., with Marxism and Freudianism - it addresses both a deep and a surface structure of a given phenomenon. In Freudianism and Marxism, the deep structure is a story - the battle between the life and death instincts, eros and tanatos (Freudianism) or the conflicts between classes that are grounded in the economic "base" (Marxism). These similarities gave rise to specific theories. Louis Althusser represents the structuralist-Marxist approach (structural Marxism) while Jacques Lacan applied structuralism to psychoanalysis.

${ }^{2}$ Somol and Whiting's metaphor refers to the acting styles of the late Robert Mitchum, representing the "projective" and Robert DeNiro, representing the "critical." As they claim, Mitchum does not act, but performs. His cool and pleasant style contrasts with the psychological labouring of DeNiro. In their own words: "Mitchum architecture' is cool, easy, and never looks like work; it's about mood or the inhibition of alternative realities [...] With Mitchum, there are scenarios, not psychodramas. The unease and anxiety of the unhomely has been replaced with the propositional alternative of the untimely" (Somol \& Whiting, 2002, p. 77).

${ }^{3}$ Situationist International was a movement rooted in Marxism and the $20^{\text {th }}$ century European artistic avant-gardes. They advocated experiences of life being alternative to those admitted by the capitalist order. For this purpose, they suggested a construction of situations - the setting up of environments favourable for the fulfilment of alternative experiences. Situationists' most influential theoretical work was "The Society of the Spectacle" (1967) by Guy Debord. Debord argued that mass media and advertising have a central position in an advanced capitalist society. Their role is to show a fake reality in order to mask the real capitalist degradation of human life. Manifesting their disapproval of such a system, the Situationist International supported the May 1968 revolts.

${ }^{4}$ In this context, it is interesting to see how Debord (1967) in his manifesto "The Society of the Spectacle" reflects on the transformations of the urban environment related to the consumerist culture. Debord essentially speaks about the same transformation of urban landscapes as Koolhaas does, but he is far from the affirmation of the ongoing processes.

"The self-destruction of the urban environment is already well under way. The explosion of cities into the countryside, covering it with what Mumford calls 'a formless mass of thinly spread semi-urban tissue', is directly governed by the imperatives of consumption. The dictatorship of the automobile [...] has left its mark on the landscape with the dominance of freeways, which tear up the old urban centers and promote an ever-wider dispersal. Within this process various forms of partially reconstituted urban fabric fleetingly crystallize around 'distribution factories' - giant shopping centers built in the middle of nowhere and surrounded by acres of parking lots. [...] But the technical organization of consumption is only the most visible aspect of the general process of decomposition that has brought the city to the point of consuming itself." (Debord, 1967, p. 174)

${ }^{5}$ Constructivism in architectural theory has at least two different meanings. It refers to 1) a research paradigm; 2) a movement/ style of modern architecture that flourished in the Soviet Union in the 1920s and early 1930s.

${ }^{6}$ As Madison (2000) argues, it is clear that Gadamer does believe in the universality (the unquestionability) of certain values. Particularly, the greatest Enlightenment value of all: freedom.

"[T] here is no higher principle of reason than that of freedom. [...] No higher principle is thinkable than that of the freedom of all [note the word "all"] and we understand actual history from the perspective of this principle: as the ever-to-be-renewed and the never-ending struggle for this freedom" (Gadamer, Philosophy in the Age of Science, as cited in: Madison, 2000). And also: "The principle of freedom is unimpugnable and irrevocable. It is no longer possible for anyone still to affirm the unfreedom of humanity. The principle that all are free never again can be shaken" (Gadamer, Philosophy in the Age of Science, as cited in Madison, 2000).

${ }^{7}$ Moral particularism is the view that there are no moral principles and that moral judgement can be found only as one considers particular cases, either real or imagined. 